\section{falmpact of Organic Matrix Compounds on the Retention of Steroid Hormone Estrone by a 'Loose' Nanofiltration Membrane}

Andrea I. Schäfer ${ }^{a^{*}}$, Long D. Nghiem ${ }^{\mathrm{b}}$, Anja Meier ${ }^{\mathrm{b}}$, Peta A. Neale ${ }^{\mathrm{a} 1}$

${ }^{a}$ School of Engineering, The University of Edinburgh, Edinburgh, EH9 3JL, United Kingdom ${ }^{b}$ School of Civil, Mining and Environmental Engineering, University of Wollongong, NSW 2522, Australia

\section{Submitted to}

Separation and Purification Technology

November 2009

\section{Abstract}

The impact of solute-solute interactions on retention and membrane adsorption of the micropollutant estrone was determined in the presence of surfactant sodium dodecyl sulphate (SDS), natural organic matter (NOM) and cellulose. A five cycle stirred cell protocol was used to study progressing saturation of a loose nanofiltration membrane with estrone. Adsorption was absent at high $\mathrm{pH}$ when the estrone molecule was dissociated, while at low and neutral $\mathrm{pH}$ the membrane was saturated a membrane was saturated after estrone retention in the presence of cellulose was observed due to estrone-cellulose partitioning SDS and NOM reduced estrone retention at low and neutral $\mathrm{pH}$ while no significant effect was visible at alkaline $\mathrm{pH}$ when solute-solute interactions were minimal. The adsorption and deposition of estrone onto the membrane was up to $50 \%$ of the total estrone in solution. Using experimental partition coefficients, the mass of estrone sorbed to organic matter as a function of $\mathrm{pH}$ was estimated. Results were similar to the total mass of estrone adsorbed to the membrane despite the partition coefficients being quantified at equilibrium ( 24 hours) while the experiment was (naturally) not. This study provides first quantifiable evidence of the impact of micropollutantorganic matter interactions in membrane filtration.

Keywords: nanofiltration, solute-solute interactions, micropollutants, estrone, membrane adsorption

\section{Introduction}

The retention of micropollutants such as hormones from water is an important issue with regards to water supplies as well as wastewater treatment and water reuse applications [1]. The retention of such compounds have been studied extensively in recent years, mostly in clean water matrices [2such compounds have been studied extensively in recent years, mostly in clean water matrices [2-
$6]$. The impact of real water matrices on retention of such contaminants is to date poorly understood 6]. The impact of real water matrices on retention of such contaminants is to date poorly understood
although matrix compounds, especially organic matter, can significantly alter retention. Anticipated mechanisms for such (positive or negative) impacts on retention are;

(i) modification of the membrane surface by matrix compounds or fouling [7-11] and hence variation of charge repulsion and sorption,

(ii) retention by a cake formed on membranes or blocked 'pores' [12-14],

(iii) increased diffusion due to accumulation in an enhanced concentration polarization layer,

(iv) interaction of micropollutants with retained matrix compounds [9, 15-19]; and

(v) solubilisation and hence reduced retention of micropollutants by non retained matrix compounds [20].

These solute-solute interactions are very complex due to the many mechanisms involved and are inherently difficult to quantify individually. The interactions depend on the variability of natural waters and on specific membrane characteristics, in particular retention. Studies on the interaction between micropollutants and sediments [21], and variability of organic characteristics [22] reflect such complexities. In consequence, membrane retention results reported in the literature are often contradictory which invites studies in well defined and controlled environments.

Various studies have reported impacts of organic matter on the retention of different micropollutants by nanofiltration (NF) and reverse osmosis (RO). Zhang et al. [23] reported a clear influence of solution matrix on pesticide retention when they examined atrazine and simazine retention in distilled, tap and river water matrices, although the precise underlying mechanisms retention in distilled, tap and river water matrices, although the precise underlying mechanisms
remain unclear. Pesticide retention was reportedly enhanced in the presence of organic matter in the remain unclear. Pesticide retention was reportedly enhanced in the presence of organic matter in the
feed solution $[18,24,25]$, however, such a phenomenon was absent in a study by Berg et al. [26] This can probably be attributed to the heterogeneity of various constituents in the aqueous solution and the diversity in physicochemical properties of the micropollutants examined. Dalton et al. [16] found that in the absence of organic matter micropollutant retention was more influenced by polarity/polarisability and hydrophobicity of the compounds, rather than their molecular weight. In contrast, in the presence of organic matter, the affinity of the micropollutant for the organic matter and in some cases the presence of calcium, affected retention by membranes. From those reported results it appears that several of the above mentioned mechanisms interplay.

Agebekodo et al. [18] found a significant increase in pesticide removal in the presence of natural organic matter (NOM) due to an increased apparent molecular weight and the appearance of negative charges. Koyuncu et al. [19] reported that NOM notably increased the retention of hormones. Possible mechanisms suggested were complexation with NOM leading to variation due to size exclusion and deposition as well as hormone-calcium complexation. McCallum et al. [27] observed increased estradiol retention in the presence of organic matter while the amount of estradiol adsorbed to the membrane decreased. Comerton et al. [28] also studied the adsorption of micropollutants on mentanes and noted that a decrease in micropollutant adsorption in the presence of organic matter was possibly due to competition with NOM for adsorption sites. Jin et al. [15] showed that the nature of organic matter was important in determining such effects. While hydrophilic dextran showed little impact of estrone retention, the presence of humic acid (HA) increased retention. It was argued that HA increased the affinity of estrone for the membrane, therefore organic matter interactions with estrone were critical. Phenolic groups played the most important role in these interactions, and this was confirmed by the findings of Neale et al. [29] regarding organic matter-water partition coefficients. 
In secondary treated effluent, and almost any natural water bodies, constituents such as organic and inorganic particles, colloids, dissolved organic matter and ions are ubiquitous, although their concentration can vary markedly. Surfactants originated from laundry, shampoo and other personal care products are also likely to be present in wastewater to some extent. Given the tendency of micropollutants to interact with such organic constituents, it is important to understand their impacts on the removal of micropollutants by membranes. Consequently, in this investigation cellulose, surfactant (sodium dodecyl sulphate) and NOM are studied are they are some of the most abundant and prominent organics.

In this study the steroidal hormone estrone was selected as a micropollutant representing the group of estrogens. Estrone is naturally excreted by humans and many animals, and is commonly found in both natural surface waters and wastewater effluent in nanogram per litre concentrations $[30,31]$. The presence of estrone in the aquatic environment can have implications for the growth and development of aquatic organisms, with studies indicating that low concentrations of estrone $(\sim 3 \mathrm{ng} / \mathrm{L})$ can cause behavioural changes in fish [32]. Estrone is a moderately hydrophobic steroidal hormone $\left(\log \mathrm{K}_{\mathrm{Ow}} 3.13\right.$ [33]) with a low water solubility. It contains monopolar and bipolar functional groups which allow for hydrogen bonding. The ketone group in the C-17 position is function $\mathrm{C}-3$ position is bipolar, meaning it can act as a hydrogen donor or acceptor. It has been widely accepted in the literature that hydrogen bonding is a primary interaction mechanism between steroid hormones such as estrone or estradiol and their receptors or biological membranes [34-38]. Laboratory studies indicate that bipolar micropollutants such as estrone can sorb moderately onto sediment [39], activated sludge [17, 40], organic and inorganic particulate matter [17], and dissolved organic matter $[29,41]$

In consequence, this paper examines the influence of feed water composition on estrone retention by using a range of organic matter types. The aim was to distinguish and quantify the contribution of micropollutant-organic matter interaction on retention.

\section{Experimental}

\subsection{Organic Compounds \& Chemical Reagents}

Radiolabelled estrone-2,4,6,7- ${ }^{3} \mathrm{H}-(\mathrm{N})(92 \%$ purity) was purchased from Sigma Aldrich (Saint Louis, $\mathrm{MO}$ ). It was supplied in a methanol solution with a specific radioactivity of $65 \mathrm{Ci} / \mathrm{mmol}$ and 100 $\mu \mathrm{g} / \mathrm{L}$ stock solution was prepared in methanol. The dissociation constant $\left(\mathrm{pK}_{2}\right)$ of estrone is 10.4 [3, 41] therefore it will become negatively charged at high $\mathrm{pH}$ values. NOM is a $\mathrm{RO}$ concentrate surface water from Mooney-Mooney Dam in Brisbane Water National Park, New South Wales, Australia, and contains a concentration of the ions found in surface water. It was extensively characterised by Schäfer [42]. Powder cellulose and analytical grade sodium dodecyl sulphate (SDS) were purchased from Sigma Aldrich (Saint Louis, U.S). Concentrations of $44 \mathrm{mgC} / \mathrm{L}$ for cellulose, $31.5 \mathrm{mgC} / \mathrm{L}$ for $\mathrm{NOM}$ and $144 \mathrm{mgC} / \mathrm{L}(1 \mathrm{mM})$ for SDS were used. The solution background electrolyte consists of $20 \mathrm{mM} \mathrm{NaCl}, 1 \mathrm{mM} \mathrm{NaHCO}_{3}$, while $1 \mathrm{M} \mathrm{HCl}$ and $1 \mathrm{M} \mathrm{NaOH}$ were used for $\mathrm{pH}$ adjustment (all reagents analytical grade purchased from Sigma Aldrich (Saint Louis, U.S)). The feed solution was prepared by adding $100 \mu \mathrm{g} / \mathrm{L}$ estrone stock solution to solution containg background electrolyte $\left(20 \mathrm{mM} \mathrm{NaCl}, 1-\mathrm{mM} \mathrm{NaHCO}_{3}\right)$ to obtain a concentration of natural hormones often encountered in domestic wastewaters. Other constituents such as cellulose, NOM or SDS were
added to the feed solution at concentrations as indicated above.

\subsection{Organic Matter - Water Partition Coefficients}

Organic matter-water partition coefficients $\left(\mathrm{K}_{\mathrm{OM}}\right)$ were used to estimate the interaction of estrone with cellulose, NOM and SDS, and they were calculated using a mass balance form of solid-phase microextration (SPME). SPME measures partitioning by extracting freely dissolved estrone while any bound to organic matter will remain in solution [43]. This has been used previously to quantify the interaction between steroidal hormones and organic matter at environmentally relevant concentrations [29, 41]. The methodology used is described in detail elsewhere [29]. Briefly, in 100 $\mathrm{mL}$ flasks radiolabelled estrone ( $3.55 \mathrm{TBq} / \mathrm{mmol}$ ) (GE Healthcare, Little Chalfont, UK) and organic matter were added to $\mathrm{MilliQ}$ grade water with a $20 \mathrm{mM} \mathrm{NaCl}, 1 \mathrm{mM} \mathrm{NaHCO}$ background electrolyte and electrolyte an 5 cher (Göttigen, Germany). A $5 \mathrm{~cm}$ length of polyacrylate SPME fibre (Polymicro Technologies, Phoenix, USA)
was added and the solution was shaken for a further 48 hours before being removed for analysis.

Using experimental $\mathrm{K}_{\mathrm{OM}}$ values $(\mathrm{L} / \mathrm{kg}$ ), the mass of estrone associated with organic matter was estimated using Equation 1,

$$
m_{O}=K_{O M} m_{W} m_{C}
$$

where $\mathrm{m}_{\mathrm{O}}$ was the mass of estrone associated with organic matter at equilibrium $(\mathrm{ng}), \mathrm{m}_{\mathrm{W}}$ was the freely dissolved estrone mass in solution (ng) and $\mathrm{m}_{\mathrm{C}}$ was the mass of organic carbon available $(\mathrm{kg})$. $\mathrm{m}_{\mathrm{w}}$ was calculated by considering the initial mass of estrone in solution, $\mathrm{m}_{\mathrm{tot}}(\mathrm{ng})$, and the fraction of freely dissolved estrone in solution at equilibrium, $\mathrm{f}_{\mathrm{w}}(\%)$ (determined from SPME experiment). While the concentrations of estrone and organic matter used in partitioning experiment). While the concentrations of estrone and organic matter used in partitioning
experiments were comparable to the membrane filtration experiments, the partition coefficients were measured after 24 hours to ensure equilibrium between estrone and organic matter was reached. The total error associated with $\mathrm{m}_{\mathrm{O}}(11.07 \%)$ was based on error propagation estimates of $\mathrm{K}_{\mathrm{OM}}, \mathrm{c}_{\mathrm{W}}, \mathrm{m}_{\mathrm{C}}$ [44]. This represented variability due to errors associated with laboratory equipment, such as micropipettes and balances and analytical techniques, such as liquid scintillation counting.

\subsection{Nanofiltration Membrane}

TFC-SR2 membranes supplied by Koch Membrane Systems (San Diego, USA) were selected for this study. TFC-SR2 is a thin film composite NF membrane with a polyamide active layer on a polysulfone support with a mean pore diameter of about $1.28 \mathrm{~nm}$ [45]. The molecular weight cut-off (MWCO) is $400 \mathrm{Da}$ [46]. Sodium chloride retention by TFC-SR2 was generally less than $10 \%$, while the membrane was designed for high organic retention. Consequently, the presence of organic matter may play an important role for estrone removal. Membrane samples were received as dry flat sheets. All membrane samples were gently rinsed prior to experiments to remove any coating and soaked in $100 \mathrm{mM} \mathrm{NaCl}$ overnight.

\subsection{Filtration System \& Experimental Protoco}

The dead end stirred system used was described in detail elsewhere [3, 42]. The inner diameter of the cell was $56.6 \mathrm{~mm}$ resulting in a membrane surface area of $21.2 \times 10^{-4} \mathrm{~m}^{2}$ and a cell volume of $200 \mathrm{~mL}$. A magnetic stirrer (Amicon) with a stirrer speed fixed at $400 \mathrm{rpm}$ was used to minimise concentration polarisation. The pressure was set and maintained using instrument-grade air. Permeate was measured using an electronic balance. Prior to each experiment, the membrane was compacted with purified water (MilliQ grade) for $1 \mathrm{~h}$ at 10 bar followed by a $30 \mathrm{~min}$ pure water filtration at 5 bar for pure water flux determination. A series of 5 fresh feed solutions, each with volume of $185 \mathrm{~mL}$, were then repetitively filtered through the mentren five subsequent filtration cycles three permeate samples of $45 \mathrm{~mL}$ each were taken for analysis. Five filtration cycles were chosen to achieve saturation of the adsorption of estrone to the membrane. The total filtration time varied from 2.5 to 5 hours, depending on the solution chemistry and presence of organic matter.

\subsection{Membrane Retention and Adsorption Calculations}

Retention is the amount of estrone or organic matter retained by the membrane and defined in Equation 2 as 


$$
R=100 \cdot\left(1-\frac{c_{P}}{c_{B}}\right)
$$

where $c_{p}$ and $c_{B}$ were permeate and cell concentrations $(\mathrm{ng} / \mathrm{L})$, respectively. In dead end stirred cell experiments, $c_{B}$ was back calculated based on a mass balance from feed, retentate and permeate sample analysis and constantly changes during the experiment. Adsorption to the membrane was sample analysis and constantly changes during the experiment. Adsorption to the membrane
ignored in the calculation and this may potentially result in a higher apparent retention value.

Adsorption on the membrane was calculated using mass balance (Equation 3) where the adsorbed mass, $\mathrm{m}_{\mathrm{A}}(\mathrm{ng})$, was

$$
m_{A}=V_{F} c_{F}-V_{P} \sum_{l}^{5} \bar{c}_{P i}-V_{R} c_{R}
$$

where $V_{F}, V_{P}$ and $V_{R}$ were the total feed, permeate and retentate volumes $(L)$ and $c_{F}, c_{p i}$ and $c_{R}$ were the feed, permeate, and retentate concentrations ( $\mathrm{ng} / \mathrm{L}$ ), respectively. Permeate ( 3 samples per cycle were averaged) and retentate (one sample per cycle) concentrations were added over 5 cycles. The results were presented specific to the membrane area as $\mathrm{m}_{\mathrm{A}} / \mathrm{A}$, where $\mathrm{A}$ was the membrane area of results were presented specific to the membrane area as $\mathrm{m}_{\mathrm{A}} / \mathrm{A}$, where $\mathrm{A}$ was the membrane area of
$21.2 \mathrm{~cm}^{2}$. The variability in retention and adsorption was determined using the variability in pure water flux. Flux was selected as it varied significantly more than other stirred cell parameters (e.g temperature or pressure) under the same conditions (e.g. $\mathrm{pH}$, pressure, background electrolyte). Using two repeat experiments, the differences between flux and retention were determined. Using these values a linear relationship was established between flux and retention, allowing variability be determined by applying the total difference in flux to the linear relationship.

\subsection{Analytical Methods}

Total organic carbon (TOC) was analysed by using a Shimadzu (Rydalmere, Australia) TOC $\mathrm{V}_{\text {CSH }}$ analyser. The instrument was set on high sensitive catalyst and NPOC (non-purgeable organic carbon) mode was used. UV absorption was measured at $254 \mathrm{~nm}$ using a UV-1700 Pharma Spectrometer (Shimadzu, Rydalmere, Australia) and $10 \mathrm{~mm}$ quartz cuvettes. Radiolabeled estrone was analysed using a Wallac 1409 liquid scintillation counter (Perkin Elmer Pty Ltd, Melbourne, Australia) with $1 \mathrm{~mL}$ of aqueous sample in $9 \mathrm{~mL}$ of Ultima Gold LLT scintillation liquid (Perkin Elmer Pty Ltd (Packard Bioscience), Melbourne, Australia). Further details of analysis are described elsewhere [3]. Salt retention was measured using an Alpha 800 conductivity meter (Courtcloud, Dover, UK)

\section{Results \& Discussion}

\subsection{Organic Matter Properties}

Organic matter properties including charge, size and functional group content can influence interactions with both the membrane and micropollutants. Consequently, the properties of the studied organic matter types are very important for membrane flux, retention, fouling, solute-solute as well as solute-membrane interactions. For this reason an in depth review of the selected organics is provided here.

Cellulose is an insoluble polysaccharide that consists of a few hundred up to a few thousand $\beta$ glucose units. Cellulose is present in wastewater from sources including toilet paper and algae. While cellulose molecules contain a large number of hydroxyl functional groups, such functional moieties are readily occupied by intra and intermolecular hydrogen bond formation between cellulose molecules themselves (see Table 1). In addition, cellulose molecules are often large and bulky, and cellulose is relatively inert to chemical interactions. Due to these characteristics the cake layer formed by the accumulation of particulate matter on the membrane surface can be very porous and may not result in measurable fouling if no other constituents are present. Consequently, the influence of cellulose on estrone retention will be largely governed by estrone-cellulose interactions or in other words the partitioning of estrone to cellulose particles.

\section{[Table 1]}

On the other hand, SDS is thought to be quite reactive. SDS is an anionic surfactant that consists of a hydrophobic tail and an anionic hydrophilic head, giving it amphiphilic properties. Therefore, surfactants can interact with a hydrophobic molecule or surface via its tail as well as partitioning into an aqueous solution due to the presence of a hydrophilic head. It has been reported that interactions between hydrophobic drugs and surfactant may cause dramatic changes in solubility or rheological behaviour of drug diffusion and penetration processes through skin and solubility or rheological behaviour of drug diffusion and penetration processes through skin and
mucous membranes [47]. In a membrane filtration system, polymer-surfactant interactions can be mucous membranes [47]. In a membrane filtration system, polymer-surfactant interactions can be
governed by (a) non-specific interactions between the non-polar surfactant tail and the hydrophobic governed by (a) non-specific interactions between the non-polar surfactant tail and the hydrophobic
backbone of the polymer (such as van der Waal forces), (b) hydrogen bonds if the membrane and surfactant possesses hydrogen donating or accepting functional groups or (c) electrostatic interactions between the polar heads of the surfactant and fixed charged groups of the polymers. Similar interactions may also be expected between micropollutants and the surfactant. , the surfactant may influence the retention mechanism of micropollutants via both solute-solute interactions or modification of membrane surface properties.

Compared to the other organics, the studied NOM is relatively undefined due to its heterogeneous nature. NOM primarily contains humic substances $(\sim 70 \%)$, as well as carbohydrates, amino acids, hydrophilic fractions and low molecular weight fractions [42]. The variability is related to the different ages and origins of NOM. As a result, NOM can contain a wide range of functional moieties such as carboxylic, phenolic, and carbonyl groups [48] as well as a wide range of molecular weights and spectroscopic properties [49]. Many studies have illustrated that the interaction of micropollutants with NOM can have implications for the behaviour and transport of micropollutant in the aquatic environment $[50,51]$.

As the different organic matter types studied all contain ionisable functional groups, the charge can be influenced by $\mathrm{pH}$. Cellulose, which primarily contains hydroxyl groups, becomes more negatively charged with increasing $\mathrm{pH}$ [52]. SDS contains negatively charged sulphate groups, and research by Childress and Elimelech [8] indicates that the addition of SDS to polymeric membranes will increase the negative charge of the membranes. NOM contains a large number of different functional groups, however, it mainly contains carboxylic moieties. Carboxylic groups dissociate around $\mathrm{pH} 4.5$ [53], therefore in neutral and alkaline $\mathrm{pH}$ conditions NOM is negatively charged. The structure of NOM can also be affected by $\mathrm{pH}$. In acidic conditions the structure of NOM is coiled, due to intramolecular hydrogen bonding. However, when NOM dissociates around neutral $\mathrm{pH}$ the structure becomes linear [22]. This change is expected to have implications for the

\subsection{Membrane Performance with Matrix Organics}

The flux ratio, which is the flux during filtration divided by the pure water flux measured at the beginning of experiments, is shown in Figure 1A as a function of $\mathrm{pH}$ for the four test solutions examined.

\section{[Figure 1]}

Results show that flux declined the most at low $\mathrm{pH}$ with a steady improvement towards higher $\mathrm{pH}$ values. Flux ratios increasing with time (ratio $>1$ ) indicate that no fouling is observed and that solutes render the membrane more hydrophilic. This can be due to the association of ions, organic matter and particularly surfactants with the membrane. In addition, the increase in flux ratio with $\mathrm{pH}$ may indicate that the increased repulsion of membrane functional groups with $\mathrm{pH}$ leads to more 
permeable membranes. At high $\mathrm{pH}$ the membrane surface charge is more negative which leads to a higher charge repulsion with some foulants. Childress and Elimelech [11] have previously observed such a flux increase in the presence of SDS with increasing $\mathrm{pH}$. NOM represents an exception to this rule with the lowest flux ratio and stable performance from neutral $\mathrm{pH}$. NOM is known to adsorb and deposit onto membranes, particularly in the presence of calcium, and is responsible for significant fouling in water treatment applications $[42,55]$.

The membrane surface charge has been published previously in background electrolyte [56] and has a typical NF profile with an isoelectric point at $\mathrm{pH} 4$ and an increasing negative charge at increasing pH up to about -10 4 where charge repulsion is minimal. Such charge repulsion affects salt retention (see Figure 1B) which is generally very low $(<20 \%)$, but shows an increasing trend with $\mathrm{pH}$ and is highest in the presence of SDS. Increased retention of salt due to SDS was also observed by Childress and Elimelech [11]

Childress and Elimelech $[8,11]$ have examined the effect of solution chemistry on the surface charge of similar membranes. The presence of HA increases the negative surface charge of the membranes at all $\mathrm{pH}$ values, which is evidenced by adsorption of such organics onto the membranes. In addition, experine Childress and Elime ( to the membrane (at low $\mathrm{pH}$ with the hydrophilic head towards the membrane, at high $\mathrm{pH}$ with the hydrophobic chain). The concentration of SDS is below the critical micelle concentration (CMC) (3.2 $\mathrm{mM}$ in $10 \mathrm{mM} \mathrm{NaCl}$ [57]), however, after 5 filtration cycles with $1 \mathrm{mM} \mathrm{SDS}$, retention could lead to SDS concentrations in excess of the CMC. This may explain the high SDS retention observed in Figure 2, as steric exclusion alone cannot justify such a high retention as the Stokes diameter of SDS is smaller than the membrane pore diameter $(0.82 \mathrm{~nm}$ vs. $1.28 \mathrm{~nm})$.

\section{[Figure 2]}

Retention results for both NOM and cellulose are also shown in Figure 2. NOM retention is measured with TOC as well as $\mathrm{UV}_{254 \mathrm{~nm}}$ absorbance. While retention of UV absorbing compounds is generally higher at $\mathrm{pH} 10$ this effect is reversed. This may be due to small neutral compounds or low molecular weight acids that cannot be measured with UV permeating through the membranes. Inorganics present in the NOM are least soluble at this $\mathrm{pH}$ and may further contribute to changes in UV absorbance. At low pH NOM retention is lowest and is most likely due to the absence of charge repulsion due to the low charge of both membranes and NOM molecules. Further, as the conformation of NOM can change with $\mathrm{pH}$, the changing size may influence retention. Cellulose cetention is compte due to the large size of particles compared to the mento pores. The retento is cope $\mathrm{D}_{10}$ value of cellulose, which represents the diamete at which $10 \%$ of the particulate matter diameter is smaller than this value, is $2.95 \mu \mathrm{m}$ [58]. In comparison, the TFC-SR2 membrane pore diameter is approximately $1.28 \mathrm{~nm}$.

\subsection{Retention of Micropollutant Estrone}

Given the considerably larger membrane pore diameter $(1.28 \mathrm{~nm})$ compared to the size of an estrone molecule (Stokes diameter of $0.82 \mathrm{~nm}$ ), the TFC-SR2 membrane is expected to exhibit relatively low estrone retention. However, due to considerable estrone adsorption to the membrane polym [59], retention at the initil filtation stage is quite high at $\mathrm{pH}$ values below the $\mathrm{NK}_{\mathrm{a}}$ of polymer [5], retention at the initial filtration stage is quite high at $\mathrm{pH}$ values below the $\mathrm{pK}_{\mathrm{a}}$ of estrone. This is evident in Figure 3 in which estrone permeate concentration as a function
cumulative permeate volume obtained by the stirred cell is shown at $\mathrm{pH} 6$ and 12 respectively.

\section{[Figure 3]}

At $\mathrm{pH} 6$ a breakthrough profile is observed which is governed by the adsorption of estrone on he membrane polymer and subsequent saturation over continuous cycles. As this adsorption is primarily due to hydrogen bonding as well as non-specific interactions, such as van der Waal forces [4]. The low charge of the membrane at this $\mathrm{pH}$, as well as the fact that the molecule is undissociated, provides ideal conditions for such adsorption. At $\mathrm{pH} 12$, above the $\mathrm{pK}_{\mathrm{a}}$ of estrone (10.4), this breakthrough phenomenon is absent and retention is stable (at 20\%) from the first cycle. After 3 filtration cycles, estrone concentrations in the permeate samples at both $\mathrm{pH} 6$ and 12 are , estrone concentrations in the permeate samples at both $\mathrm{pH} 6$ and 12 are similar, corresponding to approximately $20 \%$ estrone retention.

\subsection{Effect of Matrix Compounds on Estrone Retention}

Results reported in Figure 4 show estrone retention at $\mathrm{pH} 6$ and 12 respectively, as a function of filtration cycle as well as presence of organic matter. Some interactions of organic matter with estrone are observed.

\section{[Figure 4]}

At $\mathrm{pH} 6$ (Figure 4A), retention decreases with subsequent filtration cycles as outlined above. At this $\mathrm{pH}$ estrone is neutral and adsorbs strongly to membrane and can partition favourably to organic matter [3, 29, 41]. In the $20 \mathrm{mM} \mathrm{NaCl} 1 \mathrm{mM} \mathrm{NaHCO}_{3}$ background solution in the absence of organic matter the retention decreases from $95 \%$ to $45 \%$ after 5 cycles. Retention of estrone in the presence of cellulose remains highest at about 65\% (decreased from 92\%), while the most rapid decline is observed in the presence of NOM, from $90 \%$ to $20 \%$. Initial retention is lowest in the presence of SDS $(68 \%)$ and decreases to $28 \%$ in the fifth cycle.

Retention is influenced initially by adsorption of estrone to the membrane as well as interaction with organic solutes. The presence of some of those organic solutes leads to a modification, mostly hydrophilisation, of the membrane surface. This effect is strongest in the presence of SDS due to its amphilic nature. Further, the association of estrone with retained compounds increases retention, while the association with less retained organics may even enhance estrone permeation if this interaction is favoured over membrane adsorption. This phenomenon is illustrated in Figure 5. Retention of organics (see Figure 2) is high for SDS and cellulose, while retention is lower for NOM. SDS is the strongest contributor to surface hydrophilisation (Figure $1 \mathrm{~A})$.

\section{[Figure 5]}

At $\mathrm{pH} 12$ (Figure 4B), retention is considerably lower than at $\mathrm{pH} 6$. The membrane, organic matter and estrone are now negatively charged, hence charge repulsion limits adsorption and partitioning. Retention remains highest (about $45 \%$ ) in the presence of cellulose, while retention in the presence of other organic matter types is similar to retention in the absence of organic matter. The retention is now governed by steric hindrance and charge exclusion with both membrane adsorption and partitioning to matrix organics expected to be minimal [29]. The membrane surface modification still occurs but it is likely that it is less important than at low $\mathrm{pH}$.

Retention data as a function of $\mathrm{pH}$ in Figure 6 (cycle 1 and 5) confirms those results. In the first cycle (Figure 6A) the membranes are not yet saturated with estrone, hence adsorption govern retention. Above the $\mathrm{pK}$ of estrone (10.4) retention decreases drastically from 70 - $95 \%$ to 40 $65 \%$. While retention is consistently lower in the presence of SDS, other compounds have a more comparable retention. 
In the fifth cycle (Figure 6B), retention is notably lower as membrane adsorption is now saturated. In consequence, the impact of organic matter is now more pronounced and remains as high as $50-80 \%$ in the presence of cellulose, and retention at $\mathrm{pH} 12$ is only about $10 \%$ lower than at other $\mathrm{pH}$ values. It appears that in this case, which is most representative of long term filtration, that solute-solute interactions are in fact more important than significant variations of $\mathrm{pH}$.

\subsection{Estrone Adsorption in the Presence of Organic Matter}

While the presence of cellulose and NOM appears to have an indiscernible impact on estrone adsorption in the first filtration cycle, it is clear that estrone retention is markedly lower in the presence of surfactant (SDS) at all pH values (see Figure 6A). As discussed previously, surfactants may enhance the solubility of estrone in an aqueous solution or in other words reduce the apparent hydrophobicity of the compound. This may result in lower adsorption, and therefore lower retention in the first filtration cycle. In addition, SDS most certainly modifies the membrane surface and in consequence one would expect that adsorption would be modified depending on if the affinity consequence one would ex estrone for the surface is enhanced or decreased. It appears, from the lower retention observed, that a SDS-modified surface reduces the adsorption potential of the membrane. Results reported here are consistent with a study by Oschmann et al. [60], where SDS was reported to compete with organic matter for adsorption to ultrafiltration membranes.

In contrast, estrone retention is higher when cellulose particles are present in the feed solution. Cellulose particles are significantly larger than the membrane pore size and the accumulation of cellulose at the membrane surface will result in a porous cake layer with negligible hydraulic resistance [60] compared to the intrinsic membrane resistance (see Figure 1A). Consequently, retention enhancement observed in this case is not because of the pore blocking or pore restriction phenomena, as previously described by Schäfer et al. [61] and Jermann et al. [62] In fact, the retention enhancement observed in this case is possibly attributed to the partitioning of In fact, the retention enhancement observed in this case is possibly attributed to the partitioning of
estrone to cellulose particles [17], as well as membrane adsorption. It is currently not possible to discern between the estrone partitioned to the cellulose deposited on the membrane, adsorption of estrone to the membrane and estrone-cellulose interactions.

To consider the likelihood of interactions it is important to consider chemical characteristics in more detail. Cellulose contains hydroxyl groups, which are bipolar (hydrogen donor and acceptor), therefore it is likely that it can interact with estrone through hydrogen bonding, as estrone also contains a bipolar functional group (phenolic hydroxyl). Based on elemental stoichiometric ratios (particularly $(\mathrm{O}+\mathrm{N}) / \mathrm{C}$ ), cellulose is a polar organic [63], and this may contribute to the strength of hydrogen bonding.

At $\mathrm{pH} 12$ when estrone is an ionic species due to dissociation it is no longer bipolar. It has also been reported that cellulose particles become more negatively charged as the solution $\mathrm{pH}$ increases [52]. The combination effect results in a decrease in sorption (adsorption or partitioning) of estrone to cellulose particles. This is reflected in a lower retention at $\mathrm{pH}$ values higher than 10.4 which can indeed be seen in Figure 7 where the results of estrone adsorption to the membrane calculated using mass balance following five filtration cycles are summarised and compared to the total amount of estrone in solution. The data shows adsorption values of up to $2.5 \mathrm{ng} / \mathrm{cm}^{2}$ which is comparable with data reported by Yoon et al. [64] who showed values up to $2.4 \mathrm{ng} / \mathrm{cm}^{2}$ for vart compounds with estrone being in the order of $0.8 \mathrm{ng} / \mathrm{cm}^{2}$ which is very similar to our results.

[Figure 7]
Decreasing adsorption with increasing $\mathrm{pH}$ is expected due to charge repulsion. Adsorption does not decrease to zero at $\mathrm{pH} 12$ which may indicate that several factors govern retention at this $\mathrm{pH}$. However, caution needs to be taken as the $\mathrm{NaHCO}_{3}$ buffer is quite ineffective at $\mathrm{pH} 12$ and with the stirred cell configuration $\mathrm{pH}$ adjustment is not possible. It is likely that by the end of the experiment that the $\mathrm{pH}$ is close to $\mathrm{pH} 10$. This requires further investigation in a crossflow system.

Adsorption is highest in the presence of cellulose at all $\mathrm{pH}$ values, as well as at high $\mathrm{pH}$ values for NOM. While a general trend shows a decrease of adsorption at high $\mathrm{pH}$ (especially for pure water and SDS), the adsorption remains relatively high in the presence of NOM and cellulose. The behaviour of NOM at high pH is counter intuitive, it should be noted here that NOM contains a The behaviour of NOM at high $\mathrm{pH}$ is counter intuitive, it should be noted here that NOM contains a
high concentration of inorganic salts which are only partly soluble at such high $\mathrm{pH}$ [42]. This is expected to induce deposition of the materials and possibly charge neutrality, compared with purified humic substances that would exhibit a high negative charge at those $\mathrm{pH}$ values. Overall, up to $50 \%$ of estrone is adsorbed to the membranes and the retained organics. This can be elucidated from the total amount of estrone added to the system over 5 filtration cycles (presented as a dotted line normalised per membrane area for comparison).

The results indicate that the values are similar for pure water, NOM and SDS. However, one can expect that in the presence of SDS the adsorption to the membrane decreases due to the much higher concentration of SDS and likely competition for adsorption sites. Interaction between estrone and adsorbed SDS appears to compensate for this reduction.

$\mathrm{Hu}$ et al. [9] determined that the presence of terrestrial HA increases the adsorption of estrone to NF membrane surfaces. Adsorptions values with and without HA were $89 \%$ and 27.5\% at $\mathrm{pH} 4$ respectively. This $61.5 \%$ increase in adsorption with $\mathrm{HA}$ was highest at $\mathrm{pH} 4$ with increments being $32.0 \%$ at $\mathrm{pH} 7$ and $11.6 \%$ at $\mathrm{pH} 10.4$. This was related to the adsorption of HA to the membrane, which varied from $103.45 \mathrm{mg}$ at $\mathrm{pH} 4$ to $7.58 \mathrm{mg}$ at $\mathrm{pH} 10.4$ [9]. This change is not confirmed in our results, although the nature of HA and NOM are not identical, with terrestrial HA typically containing more carboxylic and phenolic groups compared to aquatic NOM [65]. Further one should note one should note that at $\mathrm{pH} 4$ (Figure 2) which indicates through the membrane rather than be retained and deposit. The fact that estrone retention is higher than NOM retention during the first cycle (Figure 6A) is due to estrone adsorption to the membrane, however, during the fifth cycle (Figure 6B) retention of estrone is similar to NOM retention due to estrone adsorption saturation.

\subsection{Contribution of Solute-Solute Interactions to Estrone Adsorption}

In order to try to distinguish between the adsorption of estrone to the membrane and estrone sorbed to deposited matrix compounds, organic matter-water partition coefficients $\left(\mathrm{K}_{\mathrm{OM}}\right)$ can be used to estimate the mass of estrone associated with organic matter. The concentrations of organic matter and estrone used for the $\mathrm{K}_{\mathrm{OM}}$ experiments are comparable to the membrane filtration experiments. However, it should be noted here that the partition coefficients are determined at equilibrium (24 hours followed by 48 hours to ensure estrone equilibrium with the SPME fibre). Equilibrium between organic matter and estrone should be reached at approximately 24 hours [20], therefore the membrane filtration experiments are not at equilibrium. This will affect results and hence the $\mathrm{K}_{\mathrm{OM}}$ values can only be used for estimation purposes.

The mass of estrone sorbed to the organic matrices $\left(\mathrm{m}_{\mathrm{O}}\right)$ estimated from the experimental $\mathrm{K}_{\mathrm{OM}}$ values are shown in Table 2. This is highest for NOM and a slight decrease in partitioning is observed with increasing $\mathrm{pH}$. This may be related to the increasing negative charge of NOM, and has been observed previously in the interaction between NOM and estradiol [29]. However, the error propagation calculation indicates that the change is not significant. Between $\mathrm{pH} 4$ and $8, \mathrm{~m}_{0}$ indicates $58-68 \%$ of estrone is sorbed to the organic matter. However, based on Figure 6 
considerably less estrone is retained in the presence of NOM with approximately $20-30 \%$ in the final cycle. However, as Figure 2 indicates NOM retention is lower than the other organics, it is likely that any estrone associated with NOM will also permeate through the membrane.

[Table 2]

For both cellulose and SDS $\mathrm{m}_{0}$ increases significantly from $\mathrm{pH} 6$ to 8 . For cellulose this corresponds to an increase in estrone retention from $\mathrm{pH} 6$ to 8 at cycle 5 (Figure $6 \mathrm{~B}$ ). Based on $\mathrm{m}_{0}$ approximately $13 \%$ of estrone partitions to cellulose at $\mathrm{pH} 6$, however, approximately $60 \%$ estrone retention is observed in Figure 6B. As discussed earlier, cellulose can form a porous cake layer on the membrane which may account for the increased retention of estrone observed. Finally, in the presence of SDS an increase in estrone retention from pH 6 to 8 is observed in cycle 1 (Figure 6A) which corresponds to the observation in Table 2, but not cycle 5 (Figure 6B). Further work is required to better understand solute-solute interactions in membrane filtration, and to differentiate between micropollutant sorption to organics and membrane.

\section{Conclusions}

The presence of organic matter in the feed solution strongly affects micropollutant retention by NF. The interaction is governed by a number of mechanisms namely steric hindrance, charge exclusion and modification of membrane sites. Estrone retention and adsorption to the membrane is lowest in the presence of surfactant SDS which is in agreement with SDS having the lowest KoM value. While retention enter Whenomen is absent for the loose $\mathrm{NF}$ exception of cellulose. Partitioning of estrone to cellulose particles results in a small but discernible retention enhancement due to steric hindrance as cellulose particles are completely retained by the membranes. Solute-solute interactions play an important role in governing this effect which is confirmed with $\mathrm{K}_{\mathrm{OM}}$ values. Equilibrium solute-solute interactions and membrane deposits are of similar order of magnitude. Results presented in this paper highlight the complexity of a rea membrane filtration system where micropollutants are of concern which explains the often erratic results reported in literature. Further investigations to develop quantitative methods to determine solute-solute interactions in membrane filtration and systematically differentiate between mechanisms of membrane adsorption, deposit filtration and partitioning are required.

\section{Acknowledgements}

Angelika Merschenz-Quack is thanked for the supervision of Anja Meier at her home university, Thomas Wintgens and Thomas Melin, RWTH Aachen, for their help with completion and editing of the undergraduate thesis and the BAfög Amt as well as DAAD for scholarship support. The project was part funded by the Australian Research Council (ARC) Discovery Project DP0557085. Men achem Elimech is thanked for review of the manuscipt duing his visit to Edinburgh a of Engineering Visiting Fellow. Anmalisa De Munari is acknowledge for he assistance with error calculation.

\section{References}

[1] R.P. Schwarzenbach, B.I. Escher, K. Fenner, T.B. Hofstetter, C.A. Johnson, U. von Gunten, B. Wehrli, Science. 313 (2006) 1072-1077.

B. van der Bruggen, J. Schaep, D. Wilms, C. Vandecasteele, J. Membr. Sci. 156 (1999) 2941

A.I. Schäfer, L.D. Nghiem, T.D. Waite, Environ. Sci. Technol. 37 (2003) 182-188

[4] L.D. Nghiem, A.I. Schäfer, M. Elimelech, Environ. Sci. Technol. 38 (2004) 1888-1896.
[5] B. van der Bruggen, C. Vandecasteele, Water Res. 36 (2002) 1360-1368.

[6] L.D. Nghiem, A.I. Schäfer, Environ. Eng. Sci. 19 (2002) 441-451

A.E. Childress, S.S. Deshmukh, Desalination. 118 (1998) 167-174.

A.E. Childress, M. Elimelech, J. Membr. Sci. 119 (1996) 253-268.

J.Y. Hu, X. Jin, S.L. Ong, J. Membr. Sci. 302 (2007) 188-196.

[10] P. Xu, J.E. Drewes, T.-U. Kim, C. Bellona, G. Amy, J. Membr. Sci. 279 (2006) 165-175.

[11] A.E. Childress, M. Elimelech, Environ. Sci. Technol. 34 (2000) 3710-3716.

[12] A.I. Schäfer, A.G. Fane, T.D. Waite, Water Res. 35 (2001) 1509-1517.

[13] J.E. Drewes, C. Bellona, M. Oedekoven, P. Xu, T.-U. Kim, G. Amy, Environ. Prog. 24 J.E. Drewes, C.

[14] A.R. Costa, M.N. de Pinho, M. Elimelech, J. Membr. Sci. 281 (2006) 716-725.

[15] X. Jin, J. Hu, S.L. Ong, Water Res. 41 (2007) 3077-3088.

[16] S.K. Dalton, J.A. Brant, M.R. Wiesner, J. Membr. Sci. 266 (2005) 30-39.

[17] A.I. Schäfer, M. Mastrup, R.L. Jensen, Desalination. 147 (2002) 243-250.

[18] K.M. Agbekodo, B. Legube, S. Dard, Water Res. 30 (1996) 2535-2542.

[19] I. Koyuncu, O.A. Arikan, M.R. Wiesner, C.P. Rice, J. Membr. Sci. 309 (2008) 94-101.

[20] H. Yamamoto, H.M. Liljestrand, Water Sci. Technol. 47 (2003) 77-84

[21] L. Tremblay, S.D. Kohl, J.A. Rice, J.-P. Gagné, Mar. Chem. 96 (2005) 21-34.

[22] K. Ghosh, M. Schnitzer, Soil Sci. 129 (1980) 266-276.

[23] Y. Zhang, B. Van der Bruggen, G.X. Chen, L. Braeken, C. Vandecasteele, Sep. Purif Technol. 38 (2004) 163-172

24] R. Boussahel, M. Baudu, A. Montiel, Revue des Sciences de l'Eau. 15 (2002) 709-720.

[25] E.C. Devitt, F. Ducellier, P. Cote, M.R. Wiesner, Water Res. 32 (1998) 2563-2568

[26] P. Berg, G. Hagmeyer, R. Gimbel, Desalination. 113 (1997) 205-208.

[27] E.A. McCallum, H. Hyung, T.A. Do, C.-H. Huang, J.-H. Kim, J. Membr. Sci. 319 (2008) 38-43.

[28] A.M. Comerton, R.C. Andrews, D.M. Bagley, P. Yang, J. Membr. Sci. 303 (2007) 267-277.

[29] P.A. Neale, B.I. Escher, A.I. Schäfer, Environ. Sci. Technol. 42 (2008) 2886-2892.

[30] M. Carballa, F. Omil, J.M. Lema, M. Llompart, C. García-Jares, I. Rodríguez, M. Gómez, T. Ternes, Water Res. 38 (2004) 2918-2926.

[31] D.W. Kolpin, E.T. Furlong, M.T. Meyer, E.M. Thurman, S.D. Zaugg, L.B. Barber, H.T Buxton, Environ. Sci. Technol. 36 (2002) 1202-1211.

32] C.A. Murphy, N.E. Stacey, L.D. Corkum, J. Chem. Ecol. 27 (2001) 1573-1561.

[33] C. Hansch, A. Leo, D. Hoekman, Exploring QSAR: Hydrophobic, Electronic, and Steric Constants, American Chemical Society, Washington, 1995

[34] H. Sanbe, J. Haginaka, J. Pharm. Biomed. Anal. 30 (2003) 1835-1844

[35] M. Hermansson, G. von Heijne, J. Mol. Biol. 334 (2003) 803-809.

[36] J.Y. Le Questel, G. Boquet, M. Berthelot, C. Laurence, J. Phys. Chem. B. 104 (2000) $11816-11823$

[37] W.J. Pugh, M.S. Roberts, J. Hadgraft, Int. J. Pharm. 138 (1996) 149-165.

[38] S. de Lauzon, K.M. Rajkowski, N. Cittanova, J. Steroid Biochem. Mol. Biol. 48 (1994) 225-233.

[39] K.M. Lai, K.L. Johnson, M.D. Scrimshaw, J.N. Lester, Environ. Sci. Technol. 34 (2000) 3890-3894

[40] T. Urase, T. Kikuta, Water Res. 39 (2005) 1289-1300.

[41] P.A. Neale, B.I. Escher, A.I. Schäfer, Sci. Total Environ. 407 (2009) 1164-1173.

[42] A.I. Schäfer, Natural Organics Removal Using Membranes: Principles, Performance, and Cost, CRC Press, Boca Raton, USA, 2001

43] S. Lee, J. Gan, W.P. Liu, M.A. Anderson, Environ. Sci. Technol. 37 (2003) 5597-5602.

[44] J.N. Miller, J.C. Miller, Statistics and Chemometrics for Analytical Chemistry, Prentice Hall, Harlow, 2000. 


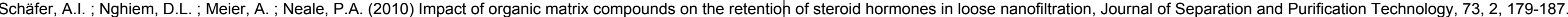
doi:10.1016/j.seppur.2010.03.023

[45] L.D. Nghiem, Removal of Emerging Trace Organic Contaminants by Nanofiltration and Reverse Osmosis, Doctor of Philosophy, University of Wollongong, 2005

[46] P. Xu, J.E. Drewes, C. Bellona, G. Amy, T.-U. Kim, M. Adam, T. Heberer, Water Environ. Res. 77 (2005) 40-48

[47] R. Barreiro-Iglesias, C. Alvarez-Lorenzo, A. Concheiro, J. Controlled Release. 93 (2003) 319-330.

[48] B. Gu, J. Schmitt, Y. Chen, L. Liang, J.F. McCarthy, Environ. Sci. Technol. 28 (1994) 3846.

[49] Y.-P. Chin, G. Aiken, E. O'Loughlin, Environ. Sci. Technol. 28 (1994) 1853-1858.

[50] S.W. Karickhoff, J. Hydraul. Eng. 110 (1984) 707-735.

[51] J.F. McCarthy, B.D. Jimenez, Environ. Sci. Technol. 19 (1985) 1072-1076

[52] W. Wang, G.G. Chase, J. Chin. Inst. Chem. Eng. 35 (2004) 5-16.

[53] K.M. Sparks, J.D. Wells, B.B. Johnson, Aust. J. Soil Res. 35 (1997) 89-101.

[54] J.S. Ra, S.-Y. Oh, B.C. Lee, S.D. Kim, Environ. Int. 34 (2008) 184-192.

[55] S. Hong, M. Elimelech, J. Membr. Sci. 132 (1997) 159-181.

[56] L.D. Nghiem, M. Elimelech, A.I. Schäfer, J. Membr. Sci. 286 (2006) 52-59.

[57] P. Mukerjee, K.J. Mysels, Critical Micelle Concentrations of Aqueous Surfactants Systems, U.S. Department of Commerce, National Bureau of Standards, Washington, DC, 1970.

(2006) 283-290.

$59]$ L.D. Nghiem, A.I. Schäfer, in: A.I. Schäfer, A.G. Fane, T.D. Waite, (Eds), Nanofiltration Principles and Applications, Elsevier, Oxford, 2004, pp. 479-520.

60] N. Oschmann, L.D. Nghiem, A.I. Schäfer, Desalination. 179 (2005) 215-223.

[61] A.I. Schäfer, A.G. Fane, T.D. Waite, Desalination. 131 (2000) 215-224

[62] D. Jermann, W. Pronk, M. Boller, A.I. Schäfer, J. Membr. Sci. 329 (2009) 75-84.

[63] R.P. Schwarzenbach, P.W. Gschwend, D.M. Imboden, Environmental Organic Chemistry, John Wiley and Sons, Hobeken, 2003.

[64] Y. Yoon, P. Westerhoff, S.A. Snyder, E.C. Wert, J. Yoon, Desalination. 202 (2007) 16-23.

[65] T.D. Gauthier, W.R. Seitz, C.L. Grant, Environ. Sci. Technol 21 (1987) 243-248.

[66] B. Xing, W.B. McGill, M.J. Dudas, Environ. Sci. Technol. 28 (1994) 1929-1933.

\section{List of Tables}

Table 1: Molecular structure and selected characteristics of steroid hormone estrone and organic matrix compounds NOM, cellulose and SDS.

Table 2: Estimation of estrone-organic interactions based of $\mathrm{K}_{\mathrm{OM}}$ values measured using solidphase microextraction. The concentrations of organic matter used are $44 \mathrm{mgC} / \mathrm{L}$ for cellulose, 31.5 $\mathrm{mgC} / \mathrm{L}$ for $\mathrm{NOM}$ and $144 \mathrm{mgC} / \mathrm{L}(1 \mathrm{mM})$ for SDS, while the estrone mass is $92.5 \mathrm{ng}$. The mass of estrone sorbed to organic $\left(\mathrm{m}_{\mathrm{O}}\right)$ is estimated using Equation 1, while the mass of estrone deposited $\left(\mathrm{m}_{\mathrm{A}}\right)$ is estimated using Equation 2. 


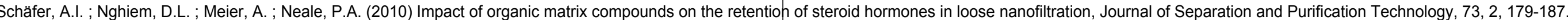
doi:10.1016/j.seppur.2010.03.023

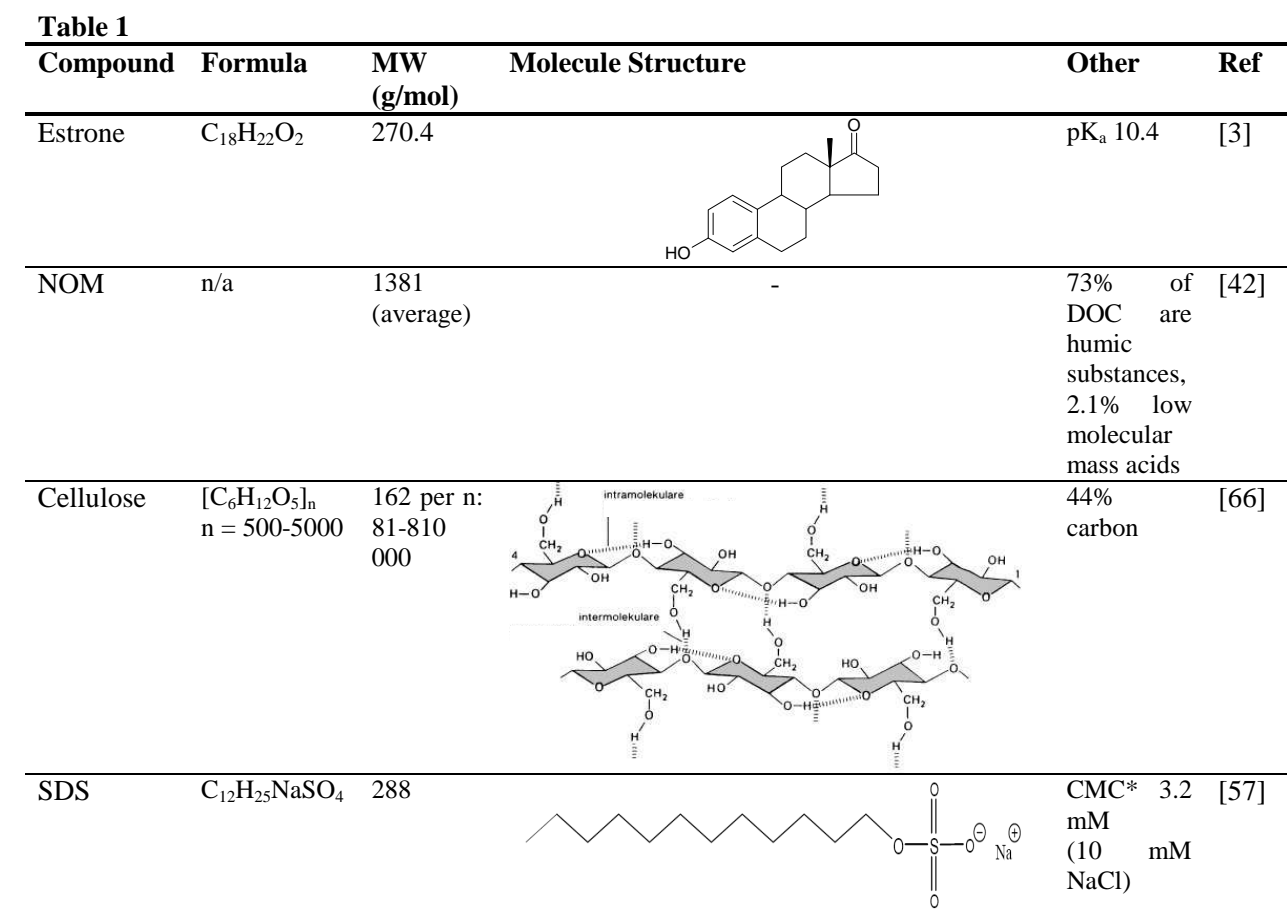

* CMC is critical micelle concentration
Table 2

\begin{tabular}{|c|c|c|c|c|c|c|}
\hline Compound & $\mathrm{pH}$ & $\begin{array}{c}\log K_{O M} \\
(\mathbf{L} / \mathbf{k g}) \pm \\
\text { T.E. }\end{array}$ & $\begin{array}{c}\mathbf{K}_{\mathrm{OM}} \\
(\mathbf{L} / \mathbf{k g}) \pm \\
\text { T.E. }\end{array}$ & $\begin{array}{c}\text { Mass of organic } \\
\text { carbon } \\
\text { available in } \\
\text { filtration cell } \\
\mathbf{m}_{\mathrm{C}}(\mathrm{g}) \\
\end{array}$ & 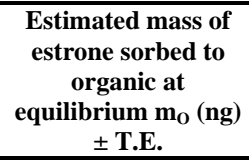 & $\begin{array}{c}\text { Mass of estrone } \\
\text { deposited } \\
\mathbf{m}_{\mathrm{A}}(\mathbf{n g})^{*}\end{array}$ \\
\hline \multirow[t]{3}{*}{ NOM } & 4 & $4.88 \pm 0.3$ & $\begin{array}{c}75878 \\
\pm 4097\end{array}$ & $31.5 \cdot 10^{-3}$ & $63 \pm 7$ & $22.5 \pm 3(\mathrm{pH} 4)$ \\
\hline & 6 & $4.74 \pm 0.3$ & $\begin{array}{r}54854 \\
\pm 2962\end{array}$ & $31.5 \cdot 10^{-3}$ & $57 \pm 6$ & $26.5 \pm 4(\mathrm{pH} 6)$ \\
\hline & 8 & $4.68 \pm 0.3$ & $\begin{array}{r}47863 \\
\pm 2585\end{array}$ & $31.5 \cdot 10^{-3}$ & $54 \pm 6$ & $\begin{array}{c}20.1 \pm 3(\mathrm{pH} 8) \\
42.0 \pm 3(\mathrm{pH} 10) \\
19.9 \pm 6(\mathrm{pH} 12)\end{array}$ \\
\hline \multirow{3}{*}{$\begin{array}{c}\text { Powder } \\
\text { Cellulose }\end{array}$} & 4 & - & - & $44 \cdot 10^{-3}$ & - & $37.3 \pm 3(\mathrm{pH} 4)$ \\
\hline & 6 & $3.59 \pm 0.2$ & $\begin{array}{l}3890 \\
\pm 210\end{array}$ & $44 \cdot 10^{-3}$ & $12 \pm 1$ & $48.8 \pm 3(\mathrm{pH} 6)$ \\
\hline & 8 & $4.76 \pm 0.3$ & $\begin{array}{r}57544 \\
\pm 3107\end{array}$ & $44 \cdot 10^{-3}$ & $52 \pm 6$ & $\begin{array}{c}46.2 \pm 3(\mathrm{pH} 8) \\
41.3 \pm 3(\mathrm{pH} 10) \\
22.5 \pm 2(\mathrm{pH} 12)\end{array}$ \\
\hline \multirow{3}{*}{ SDS } & 4 & - & - & $144 \cdot 10^{-3}$ & - & $16.4 \pm 5(\mathrm{pH} 4)$ \\
\hline & 6 & $2.89 \pm 0.2$ & $\begin{array}{l}776 \\
\pm 42\end{array}$ & $144 \cdot 10^{-3}$ & $8 \pm 1$ & $22.5 \pm 3(\mathrm{pH} 6)$ \\
\hline & 8 & $4.12 \pm 0.2$ & $\begin{array}{r}13183 \\
\pm 712\end{array}$ & $144 \cdot 10^{-3}$ & $49 \pm 5$ & $\begin{array}{r}24.2 \pm 3(\mathrm{pH} 8) \\
12.9 \pm 5(\mathrm{pH} 10)\end{array}$ \\
\hline
\end{tabular}

T.E. is total error calculated using error propagation techniques; Initial mass of estrone in the feed is $92.5 \mathrm{ng}$ $* \mathrm{~m}_{\mathrm{A}}$ in the absence of organic matter was $26.7 \mathrm{ng} \pm 4(\mathrm{pH} 4), 24.4 \mathrm{ng} \pm 3(\mathrm{pH} 6), 25.9 \mathrm{ng} \pm 4(\mathrm{pH} 8)$ and 8.7 $\operatorname{ng} \pm 6(\mathrm{pH} 10)$ 


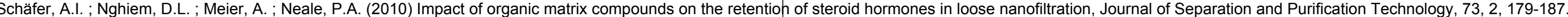
doi:10.1016/j.seppur.2010.03.023

\section{List of Figures}

Figure 1: a) Ratio of flux after cycle 5 (average of 3 readings at sampling) to pure water flux before experiment and b) salt retention after cycle 5 (average of 3 readings at sampling). The solutions are $100 \mathrm{ng} / \mathrm{L}$ estrone in $20 \mathrm{mM} \mathrm{NaCl} 1 \mathrm{mM} \mathrm{NaHCO}_{3}$, estrone with $31.5 \mathrm{mgC} / \mathrm{L} \mathrm{NOM}$, estrone with 44 $\mathrm{mgC} / \mathrm{L}$ cellulose and estrone with $144 \mathrm{mgC} / \mathrm{L}$ SDS (Error bars indicate percent error).

Figure 2: Retention of matrix compounds NOM, cellulose and SDS measured with TOC and UV Values are for cycle 5 with values representing average of 3 samples (same conditions as Figure 1) (Error bars indicate experimental variation).

Figure 3: Permeate concentration as a function of filtered volume at $\mathrm{pH} 6$ and $\mathrm{pH} 12$ (Clean background electrolyte contains $100 \mathrm{ng} / \mathrm{L}$ estrone, $20 \mathrm{mM} \mathrm{NaCl} 1 \mathrm{mM} \mathrm{NaHCO}_{3}$ ).

Figure 4: Estrone retention by the TFC-SR2 membrane at a) pH 6 and b) pH 12 (Clean background electrolyte contains $100 \mathrm{ng} / \mathrm{L}$ estrone, $20 \mathrm{mM} \mathrm{NaCl} 1 \mathrm{mM} \mathrm{NaHCO}_{3}$; organic solutions contains 31.5 $\mathrm{mgC} / \mathrm{L}$ of NOM, $44 \mathrm{mgC} / \mathrm{L}$ of cellulose, and $144 \mathrm{mgC} / \mathrm{L}$ SDS in background electrolyte solution) (Error bars indicate experimental variation)

Figure 5: Schematic of effect of organics on micropollutant retention.

Figure 6: Effects of various constituents on estrone retention by the TFC-SR2 membrane as a 6: $\mathrm{pH}$ in the a) first filtration cycle and b) fifth filtration cycle (same conditions as Figure

Figure 7: Adsorption of estrone to membrane calculated by mass balance (same conditions as Figure 4)
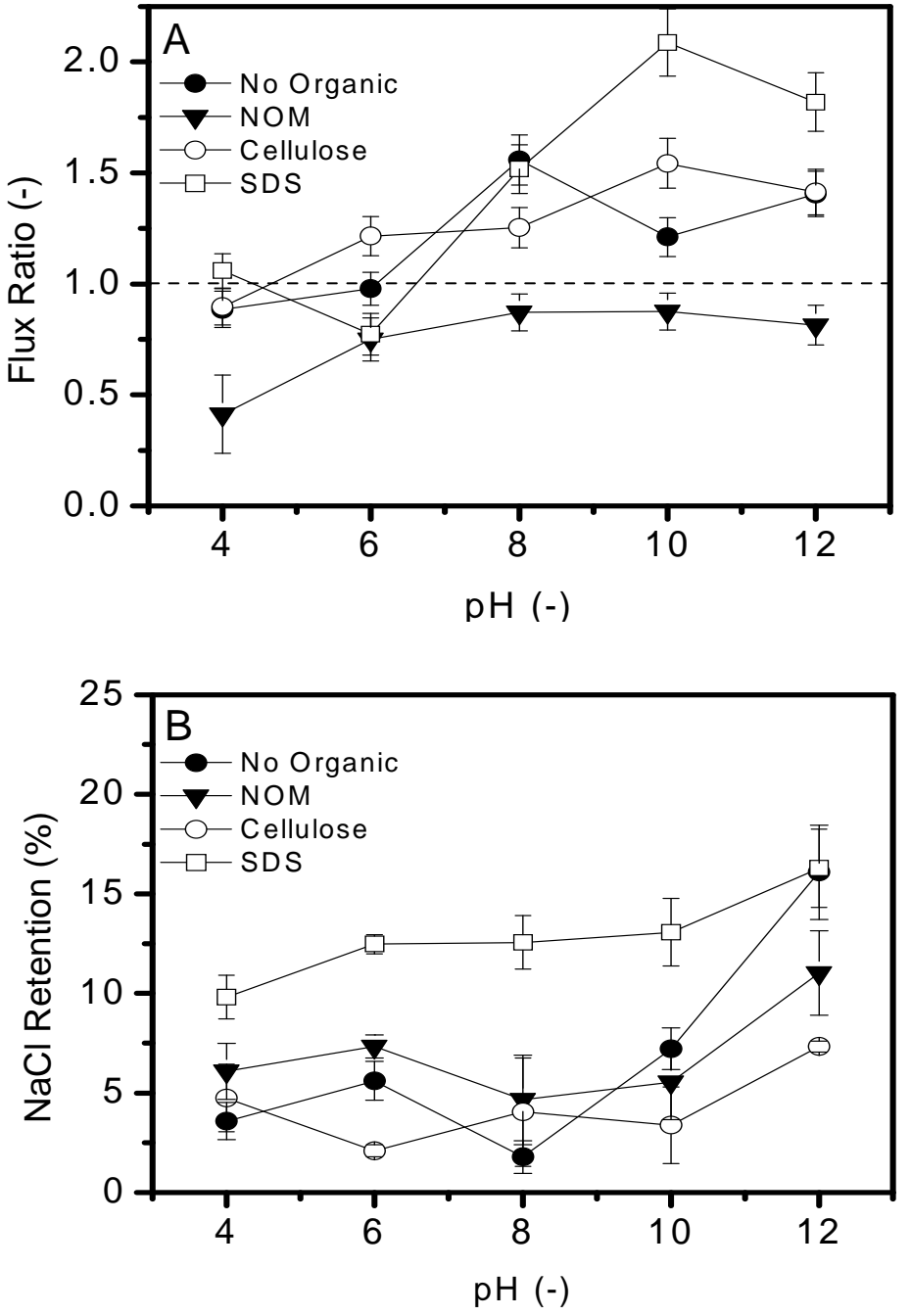


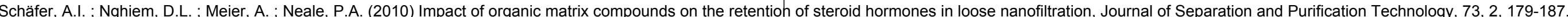
doi:10.1016/j.seppur.2010.03.023

Figure 2
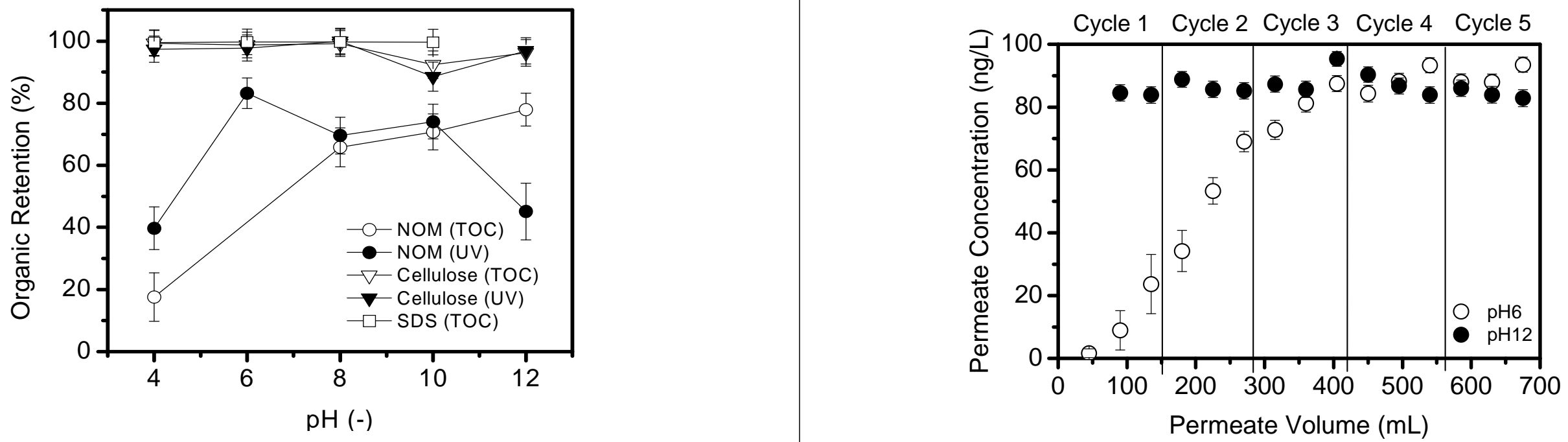


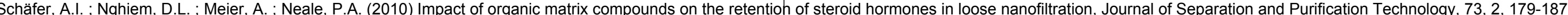
doi:10.1016/j.seppur.2010.03.023

Figure 4

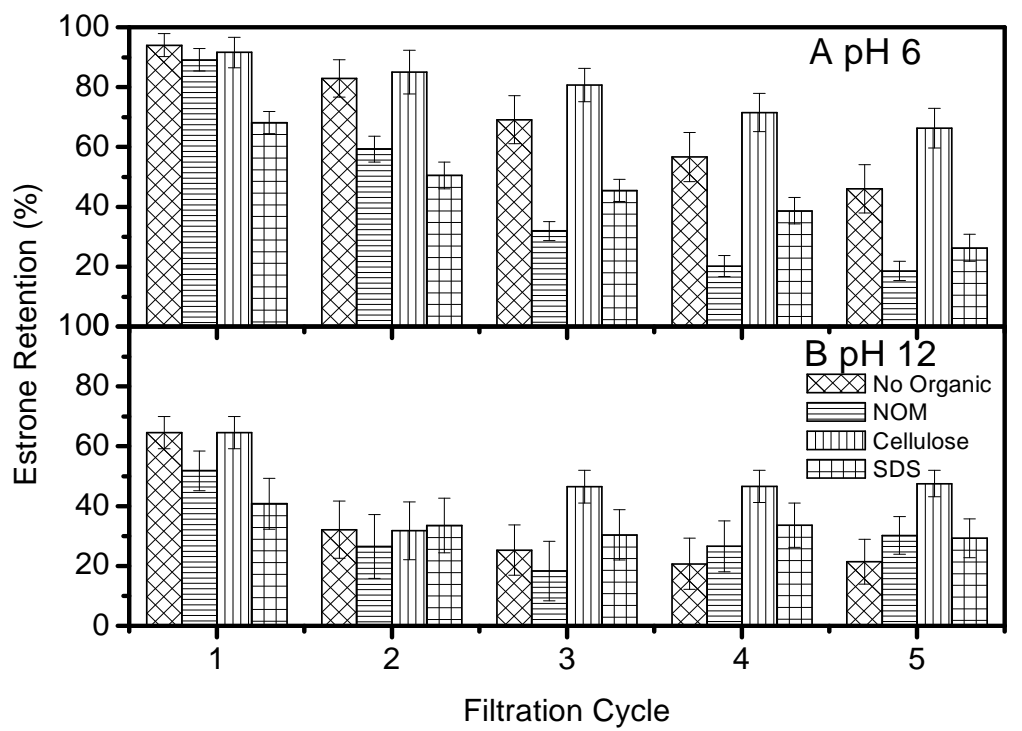

Figure 5

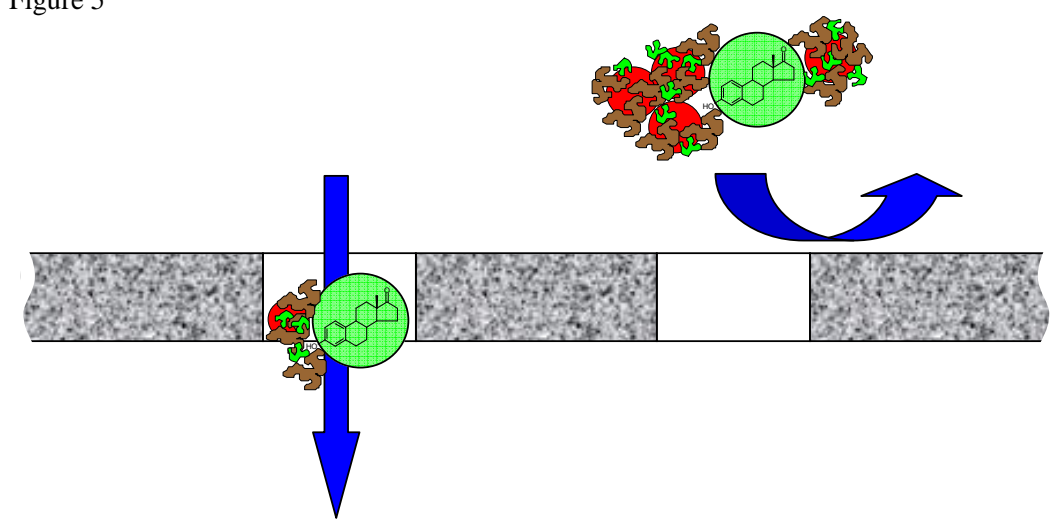




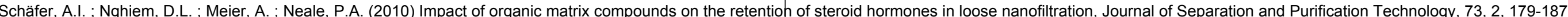
doi:10.1016/j.seppur.2010.03.023

Figure 6

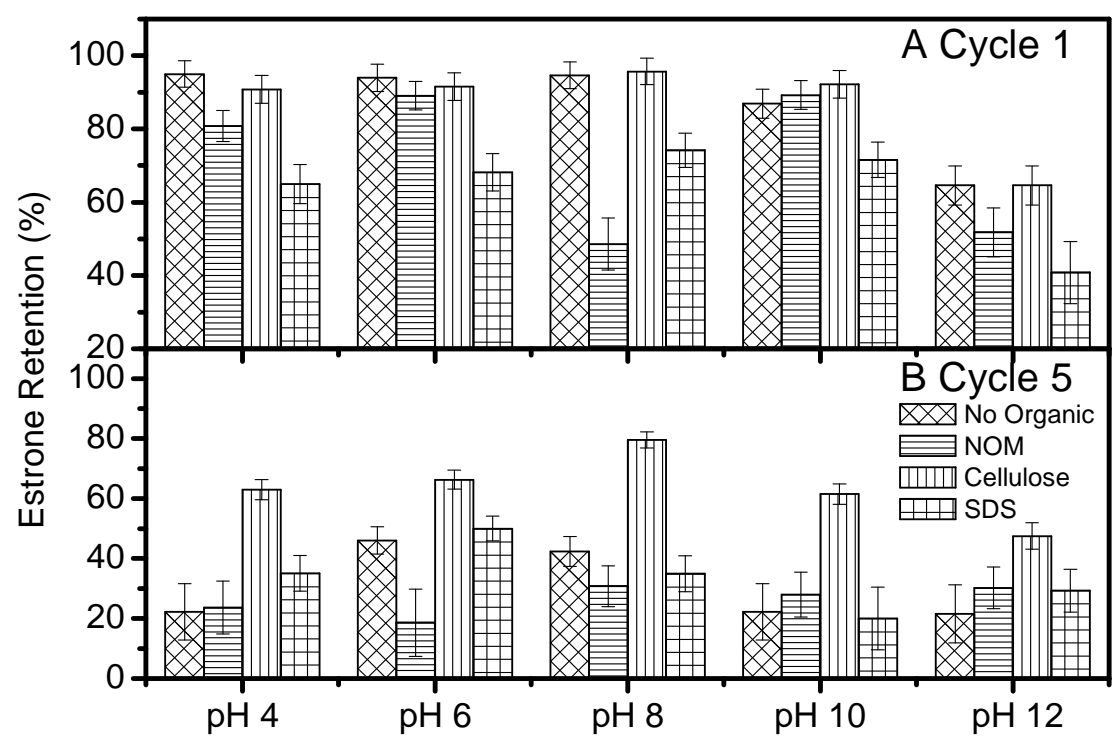

Figure 7

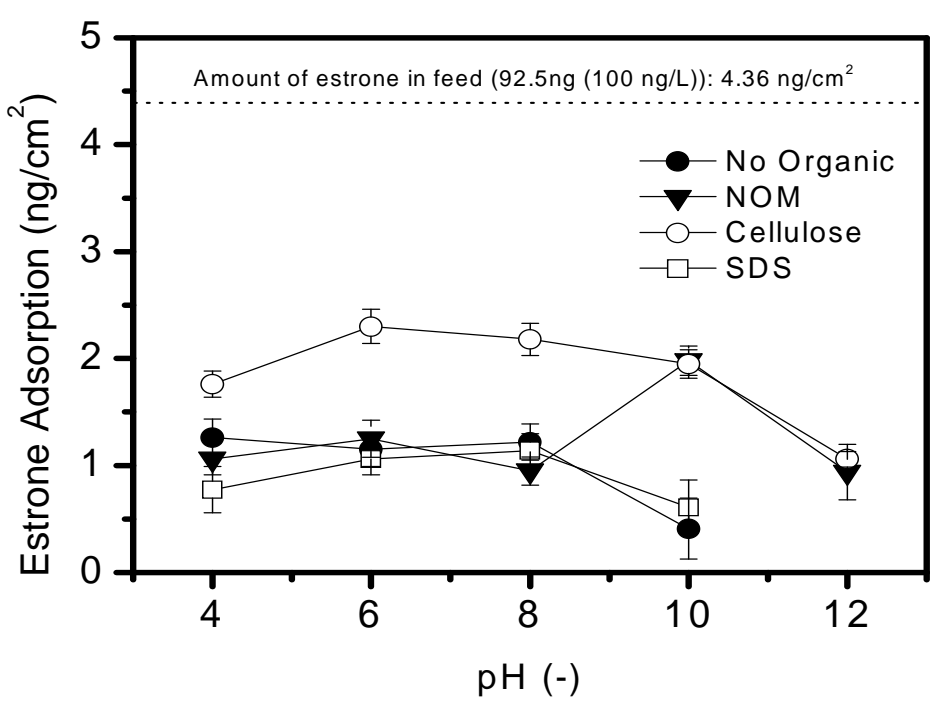

